\title{
FAKTOR-FAKTOR YANG MEMPENGARUHI PEMBERIAN ASI EKSKLUSIF PADA IBU PEKERJA
}

\section{Sri Melda Br Bangun, Putri Damayanti Damanik, Basyariah Lubis}

Institut Kesehatan Medistra Lubuk Pakam

Jl. Sudirman No. 38 Lubuk Pakam Kab. Deli Serdang

Email: meldabangun24@gmail.com

\section{DOI : https://doi.org/10.35451/jkg.v3i1.500}

\begin{abstract}
Exclusive breastfeeding is breastfeeding for the first 6 months without drinks or eat other food additives. The low exclusive breastfeeding is a reason for the high infant mortality rate in Indonesia. The research aims to know the factors that effect of giving exclusive breastfeeding toward working mothers at Grandmed Hospital Lubuk Pakam such as the supporting of husband, breastfeeding place facilities, and the additional rest time. This research included an analytic observational quantitative study with a cross sectional design. The population is 21 person of working mothers. Data collection techniques are used questionnaires. The statistical test used in this research is chi-square and simple linear regression. The theoretical basis is the Green and Kreutzer Behavior Theory (1980). Based on the results and analysis of research, it was found that the majority of respondents aged are 26-30, with last education is D3, and they had babies aged 1-2 months. A total of $66.7 \%$ provide exclusive breastfeeding. There is a relationship of supporting husband with the giving of exclusive breastfeeding. The most dominant factor influenced giving of exclusive breastfeeding is husband's support factor where $p$-value $=0,012<a(0.05)$. It is suggest for management of Grandmed Hospital to provide facilities that support Breastfeeding Corner like a icebox in the workplace and provide the opportunity to express milk during working hours.
\end{abstract}

\section{Keywords: Exclusive Breastfeeding, Breastfeeding Corner, and The Rest Time}

Supporting of Husband, 
Received: 05 OKtober 2020 :: Accepted: 09 Oktober 2020 :: Published: 31 Oktober 2020

\section{Pendahuluan}

Air susu ibu (ASI) merupakan makanan utama bagi bayi. ASI ini menjadi sumber utama kehidupan bayi sampai usia 6 bulan. Selama 6 bulan diupayakan bayi hanya minum ASI saja tanpa ada tambahan lainnya atau sering disebut ASI Eksklusif. Selama itu bayi diharapkan tidak mendapatkan tambahan cairan lain seperti susu formula, air teh, madu, air putih, dan tanpa makanan pendamping (Habiba, 2016). Setelah memasuki usia lebih dari 6 bulan, bayi sudah mulai diperkenalkan makanan tambahan karena pada usia ini bayi sudah bisa mengkonsumsi makanan selain ASI dengan tetap memperhatikan asupan yang dibutuhkan bayi.

World Health Organization (WHO)

dan United Nations Childrens Fund (UNICEF) merekomendasikan melakukan inisiasi menyusui dalam satu jam pertama kehidupan, menyusui sesuai permintaan atau sesering yang diinginkan bayi, dan tidak menggunakan botol, dot, dan empeng (Infodatin, 2018). Menurut data (WHO, 2016) cakupan ASI Eksklusif di seluruh dunia hanya sekitar $36 \%$ selama periode 2007-2014. Persentase ASI Eksklusif bayi usia 0-6 bulan tahun 2018 mengalami peningkatan menjadi sekitar 40\% (WHO, 2018). Secara global pada tahun 2018, diperkirakan anak-anak yang akan mengalami stunting sebanyak 149 juta anak, 49 juta diperkirakan terhambat untuk tinggi, dan 40 juta yang kelebihan berat badan atau obesitas (WHO, 2018). Situasi gizi balita di dunia saat ini sebanyak 155 juta balita pendek (stunting), 52 juta balita kurus (wasting), dan 41 juta balita gemuk (overweight) (Infodatin, 2018). Di Indonesia, berdasarkan hasil Riset Kesehatan Dasar (Riskesdas) tahun 2018 , terdapat $17,7 \%$ balita mengalami gizi buruk dan gizi kurang, sebanyak $30,8 \%$ balita sangat pendek dan pendek, dan sebanyak 10,2\% balita sangat kurus dan kurus, kemudian sebanyak $8 \%$ balita gemuk. Menanggapi masalah gizi buruk dan gizi kurang, terdapat target Rencana Pembangunan Jangka Menengah Nasional (RPJMN) yaitu 17\% (Riskesdas, 2018). Masalahmasalah gizi diatas pada balita tersebut dapat dicegah dengan melakukan pemberian ASI secara eksklusif (Infodatin, 2018). Penelitian mengenai faktor-faktor yang mempengaruhi pemberian ASI Eksklusif terhadap ibu telah banyak dilakukan, tetapi sangat jarang yang meneliti pada tenaga kesehatan perempuan. Berdasarkan survey pendahuluan yang didapakan di RS Grandmed Lubuk Pakam masih terdapat ibu bekerja yang belum semua menerapkan pemberian ASI secara eksklusif meskipun bekerja dibidang kesehatan dan di Rumah Sakit khususnya.

\section{METODE PENELITIAN}

Jenis penelitian yang digunakan yaitu penelitian kuantitatif dengan pendekatan survey analitik, dan menggunakan desain penelitian yaitu cross sectional yang bertujuan mengetahui pengaruh dukungan suami, tersedianya fasilitas pojok ASI, dan penambahan waktu istirahat diwaktu yang sama. Populasi dalam penelitian ini 
Received: 05 OKtober 2020 :: Accepted: 09 Oktober 2020 :: Published: 31 Oktober 2020

seluruh ibu bekerja yang memiliki bayi usia 0-6 bulan di Rumah Sakit Grandmed Lubuk Pakam yang berjumlah 21 orang. Pengambilan sampel dengan menggunakan teknik Total sampling yaitu seluruh populasi dijadikan sampel. Pengumpulan data dengan menggunakan data primer dan data sekunder. Wawancara kepada responden dengan berpedoman pada kuesioner yang telah dipersiapkan merupakan teknik yang digunakan dalam mengumpulkan data primer. Sedangkan data sekunder diperoleh dari bagian HRD di Rumah Sakit Grandmed Lubuk Pakam yaitu data tentang jumlah ibu bekerja di RS Grandmed Lubuk Pakam. Setelah data terkumpul. kemudian diolah dengan menggunakan uji chi-square dengan tingkat kepercayaan 95\% (alpha=5\%) dan dilanjutkan dengan menggunakan uji regresi linear sederhana (simple linear regression) setelah dilakukan seleksi variabel yang memiliki nilai $p<0,025$ pada uji bivariate dengan kepercayaan $95 \%$ (alpha $=5 \%$ ). Dasar pengambilan keputusan dengan ketentuan jika nilai $p$ $<$ a maka Ho ditolak yang dapat disimpulkan bahwa terdapat hubungan antara variabel independent dengan dependent.

\section{HASIL}

Tabel 1. Karakteristik Responden Berdasarkan Umur, Pendidikan, dan Usia Bayi pada Ibu Bekerja dengan jumlah sampel 21 orang

\begin{tabular}{ccc}
\hline Umur & $\mathbf{f}$ & $\mathbf{\%}$ \\
\hline $20-25$ & 7 & 33,3 \\
$26-30$ & 11 & 52,4 \\
$31-35$ & 3 & 14,3 \\
\hline Pendidikan & $\mathbf{f}$ & $\mathbf{\%}$ \\
\hline SMA & 2 & 9,5 \\
D3 & 11 & 52,4 \\
S1 & 8 & 38,1 \\
\hline Usia Bayi & $\mathbf{f}$ & $\mathbf{\%}$ \\
\hline 1-2 Bulan & 8 & 38,1
\end{tabular}

\begin{tabular}{lll} 
3-4 Bulan & 7 & 33,3 \\
5-6 Bulan & 6 & 28,6 \\
\hline
\end{tabular}

Dari tabel 1 menunjukkan jumlah responden berdasarkan umur responden, mayoritas responden yang berumur 26-30 tahun sebanyak 11 orang $(52,4)$. Jumlah responden berdasarkan pendidikan terakhir didapatkan mayoritas responden yang memiliki pendidikan terakhir D3 sebanyak 11 orang $(52,4 \%)$. Mayoritas responden yang memiliki bayi adalah usia usia 1-2 bulan sebanyak 8 orang $(38,1)$.

Tabel 2 Distribusi Frekuensi Responden Berdasarkan Dukungan Suami, Tersedianya Fasilitas Pojok ASI, dan Penambahan Waktu Istirahat

\begin{tabular}{ccc}
\hline $\begin{array}{c}\text { Dukungan } \\
\text { Suami }\end{array}$ & f & \% \\
\hline Kurang & 0 & 0,0 \\
Sedang & 10 & 47,6 \\
Baik & 11 & 52,4 \\
\hline Fasilitas & f & \% \\
Pojok ASI & & \\
\hline Tidak Ada & 10 & 47,6 \\
Ada & 11 & 52,4 \\
\hline Penambahan & f & $\%$ \\
Waktu & & \\
Istirahat & & \\
\hline Tidak Ada & 17 & 81,0 \\
Ada & 4 & 19,0 \\
\hline Kategori & f & \% \\
\hline Tidak & 7 & 33,3 \\
Eksklusif & & \\
Eksklusif & 14 & 66,7 \\
\hline
\end{tabular}

Dari tabel 2 diatas diapatkan dukungan suami mayoritas responden memiliki dukungan suami baik yaitu sebanyak 11 orang (52,4\%). Berdasarkan fasilitas pojok ASI yang telah dikategorikan didapatkan bahwa mayoritas responden menjawab ada 
Jurnal Kesehatan Masyarakat \& Gizi, e-ISSN: 2655-0849

Vol. 3 No.1 Edisi Mei-Oktober 2020

https://ejournal.medistra.ac.id/index.php/JKG

Received: 05 OKtober 2020 :: Accepted: 09 Oktober 2020 :: Published: 31 Oktober 2020

fasilitas pojok ASI di tempat kerja sebanyak 11 orang $(52,4 \%)$. Tentang penambahan waku istirahat yang telah dikategorikan didapatkan bahwa mayoritas responden menjawab tidak ada penambahan waktu istirahat ditempat kerja sebanyak 17 orang $(81,0 \%)$. 
Tabel 3 Hubungan Dukungan Suami dengan Pemberian ASI Eksklusif pada Ibu Bekerja di RS Grandmed Lubuk Pakam

\begin{tabular}{|c|c|c|c|c|c|c|c|}
\hline \multirow{3}{*}{$\begin{array}{c}\text { Dukungan } \\
\text { suami }\end{array}$} & \multicolumn{4}{|c|}{ Pemberian ASI } & \multirow{2}{*}{\multicolumn{2}{|c|}{ Total }} & \multirow{3}{*}{$p$} \\
\hline & \multicolumn{2}{|c|}{ Eksklusif } & \multicolumn{2}{|c|}{$\begin{array}{c}\text { Tidak } \\
\text { Eksklusif }\end{array}$} & & & \\
\hline & $f$ & $\%$ & $f$ & $\%$ & $\mathrm{~F}$ & $\%$ & \\
\hline Baik & 10 & 90,1 & 1 & 9,1 & 11 & 100 & 0,024 \\
\hline Sedang & 4 & 40,0 & 6 & 60,0 & 10 & 100 & \\
\hline
\end{tabular}

Dari tabel 3 didapakan hasil bahwa terdapat hubungan dukungan suami dengan pemberian ASI Eksklusif dikarenakan nilai $p$-value $(0,024<0,05)$.

Tabel 4 Hubungan Tersedianya Fasilitas Pojok ASI dengan Pemberian ASI Eksklusif di RS Grandmed Lubuk Pakam Deli Serdang Tahun 2020

\begin{tabular}{cccccccc}
\hline \multirow{2}{*}{$\begin{array}{c}\text { Tersedianya Pojok } \\
\text { ASI }\end{array}$} & \multicolumn{9}{c}{ Pemberian ASI } & \multirow{2}{*}{ Total } & \multirow{2}{*}{ P } \\
\cline { 2 - 7 } & $\mathrm{f}$ & Eksklusif & \multicolumn{3}{c}{ Tidak Eksklusif } & & \\
\hline Ada & 8 & 72,7 & 3 & 27,3 & 11 & 100 & \multirow{2}{*}{0,659} \\
Tidak & 6 & 60,0 & 4 & 40,0 & 10 & 100 & \\
\hline
\end{tabular}

Dari tabel 4 didapatkan hasil bahwa tidak ada hubungan tersedianya fasilitas pojok ASI dengan pemberian ASI Ekslusif dikarenakan nilai $p$-value $(0.659>0,05)$.

Tabel 5 Hubungan Penambahan Waktu Istirahat dengan Pemberian ASI Eksklusif di RS Grandmed Lubuk Pakam Deli Serdang Tahun 2020

\begin{tabular}{|c|c|c|c|c|c|c|c|}
\hline \multirow{3}{*}{$\begin{array}{c}\text { Penambahan Waktu } \\
\text { Istirahat }\end{array}$} & \multicolumn{4}{|c|}{ Pemberian ASI } & \multirow{2}{*}{\multicolumn{2}{|c|}{ Total }} & \multirow{3}{*}{$p$} \\
\hline & \multicolumn{2}{|c|}{ Eksklusif } & \multicolumn{2}{|c|}{$\begin{array}{c}\text { Tidak } \\
\text { Eksklusif }\end{array}$} & & & \\
\hline & $f$ & $\%$ & $f$ & $\%$ & $f$ & $\%$ & \\
\hline Ada & 4 & 100 & 0 & 0 & 4 & 100 & 0255 \\
\hline Tidak & 10 & 58,8 & 7 & 41,2 & 17 & 100 & 0,255 \\
\hline
\end{tabular}

Dari tabel 5 diatas dapat disimpulkan bahwa tidak ada hubungan penambahan waktu istirahat dengan pemberian ASI Eksklusif dikarenakan nilai $p$-value $(0,255>0,05)$. 
Tabel 6 Pengaruh Dukungan Suami Terhadap Pemberian ASI Eksklusif di RS Grandmed Lubuk Pakam Deli Serdang Tahun 2020

\begin{tabular}{llcccc}
\hline \multicolumn{1}{c}{ Variabel } & B & SE & Exp (B) & \multicolumn{1}{c}{ T } & \multicolumn{1}{c}{ Sig } \\
\hline (constant) & .382 & .469 & & .814 & .426 \\
Dukungan suami & .509 & .182 & .539 & 2.792 & .012 \\
\hline
\end{tabular}

Dari tabel 6 didapatkan kesimpulan bahwa nilai sig variabel dukungan suami $<0,05(0,012<0,05)$ dan nilai t hitung $>$ $t$ tabel $(2,792>0,814)$ yang artinya bahwa Ha diterima yaitu ada pengaruh dukungan suami terhadap pemberian ASI eksklusif. Dalam hal ini faktor tersedianya fasilitas pojok ASI dan penambahan waktu istirahat tidak dimasukkan dalam uji statistic dikarenakan tidak memenuhi syarat uji statistic regresi linier sederhana (simple linear regression) yaitu nilai $p$ value $<0,025$ dalam uji bivariate. Dari persamaan (1) didapatkan hasil penelitian didapatkan persamaan :

$\hat{Y}=a+b X$

$\hat{Y}=0,382+0,509 X$

Dari persamaan tersebut dapat dijelaskan bahwa konstanta sebesar 0,382; artinya jika dukungan suami (X) nilainya adalah 0 , maka pemberian ASI Eksklusif $(\hat{Y})$ nilainya positif sebesar 0,382 . Koefisien regresi variabel nilai $(X)$ sebesar 0,509; artinya jika nilai mengalami kenaikan 1, maka pemberian ASI $(\hat{Y})$ akan mengalami peningkatan sebesar 0,509. Koefisien bernilai positif artinya terjadi hubungan positif antara dukungan suami dengan pemberian ASI Eksklusif, semakin tinggi nilai dukungan suami, maka semakin tinggi juga pemberian ASI Eksklusif

\section{PEMBAHASAN}

Berdasarkan hasil penelitian yang dilakukan terhadap 21 responden ibu bekerja yang memiliki bayi usia 0-6 bulan di Rumah Sakit Grandmed Lubuk Pakam didapatkan usia mayoritas adalah 26-30 tahun sebanyak 5 orang $(52,4 \%)$. Menurut Hidajati dalam
(Kusumaningram, 2016) usia $20-35$ tahun dikenal usia aman untuk kehamilan, persalinan, dan menyusui, sehingga sesuai dengan masa reproduksi sangat baik dan sangat mendukung dalam pemberian ASI eksklusif jadi semakin cukup umur maka tingkat kematangan dan kekuatan seseorang akan lebih matang dalam berpikir dan bekerja.

Dari hasil penelitian ini menunjukkan pengetahuan tentang pemberian ASI eksklusif pada ibu bekerja di Rumah Sakit Grandmed Lubuk Pakam yang memberikan ASI eksklusif sebagian besar adalah berpendidikan terakhir D3 sebanyak 11 orang (52,4\%). Tingginya jumlah responden yang memberikan ASI ekslusif responden diduga disebabkan tidak lain diantaranya adalah tingginya pendidikan terakhir yang responden miliki. Hal ini sesuai dengan penelitian sebelumnya oleh Green (1980) dalam (Notoatmodjo, 2014) yang mengemukakan bahwa tingkat pendidikan merupakan faktor predisposisi untuk berperilaku. Dari hasil tersebut menyatakan bahwa jumlah ibu bekerja lebih banyak memiliki bayi usia 1-2 bulan.

Berdasarkan hasil penelitian yang dilakukan terhadap 21 responden ibu bekerja yang memiliki bayi usia 0-6 bulan didapatkan mayoritas responden yang memberikan ASI secara ekslusif sebanyak 14 orang $(66,7 \%)$ dengan jumlah responden yang menjawab penambahan waktu istirahat paling banyak adalah tidak sebanyak 10 orang $(47,7 \%)$ dan minoritas responden yang tidak memberikan ASI ekslusif yaitu sebanyak 7 orang $(33,3 \%)$ dengan 
Received: 05 OKtober 2020 :: Accepted: 09 Oktober 2020 :: Published: 31 Oktober 2020

jumlah responden yang menjawab penambahan waktu istirahat paling banyak adalah tidak sebanyak 7 orang $(33,3 \%)$. Hal ini menunjukkan kebanyakan yang memberikan ASI ekslusif adalah ibu bekerja yang menjawab tidak ada penambahan waktu istirahat.

Penelitian Anderson KL \& Wallace LM, 2006 dalam (Septiasari, 2017) ditemukan di Nairobi Kennya ibu bekerja antara empat sampai 12 bulan post partum mencapai 94,1 \% menyusui Eksklusif didukung oleh kebijakkan yang memberi kesempatan menyusui bayi mereka pada saat istirahat atau saat bekerja. Ibu akan lebih memilih menyusui jika ada kebijakan menyediakan kamar menyusui dan tersedia alat pompa ASI di tempat kerja mereka.

Berdasarkan hasil uji statistic yang dilakukan didapatkan kesimpulan mayoritas tidak berpengaruh yaitu variabel independen tersedianya pojok ASI dan penambahan waktu istirahat tidak berpengaruh terhadap pemberian ASI ekslusif karena karena nilai signifikan masing-masing variabel $>0,05$ dan nilai $t$ hitung $<\mathrm{t}$ tabel. Hanya variabel dukungan suami yang memiliki pengaruh terhadap pemberian ASI eksklusif yaitu nilai signifikan $(0,012<0,05)$ dan nilai $t$ hitung $>$ tabel $(2,792>0,814)$.

Suami, selain bisa menjadi faktor pendukung sekaligus justru bias menjadi faktor penghambat. Keinginan ibu untuk memberikan ASI Eksklusif sebaiknya sudah didiskusikan dengan keluarga terutama orang-orang yang akan tinggal bersama ibu saat bayi itu lahir tentunya seorang suami jauh sebelum si bayi lahir atau minimal saat fase kehamilan. Tanamkan kepada keluarga pentingnya ASI, bagaimana cara memberikan ASI Ekslusif, serta dukungan apa yang mereka bias berikan. Hal ini menjadi penting dikarenakan pada beberapa kasus kegagalan seorang ibu dalam memberikan ASI Ekslusif justru karena pemahaman yang salah dari keluarga ataupun orang sekitar yang pada saat itu ikut serta dalam menjaga bayi, seperti halnya memberikan air putih kepada bayi supaya bayi tidak kuning atau menambahkan bayi dengan susu formula karena bayi menangis dan beranggapan bahwa bayi masih lapar dan saat itu si ibu bayi kesulitan menolak atau menentang karena yang memberikan adalah orang yang mereka segani. Peristiwa ini bias diminimalisir saat ibu maupun keluarga bahkan oran-orang terdekat dengan bayi memiliki pengetahuan tentang ASI yang baik serta kesepakatan dan komitmen yang kuat untuk mendukung ibu dalam memberikan ASI Eksklusif.

Peneliti berasumsi bahwa faktor tersedianya fasilitas pojok ASI dan adanya penambahan waktu istirahat tidak berpengaruh langsung terhadap pemberian ASI Eksklusif dikarenakan faktor individu ibunya sendiri seperti adanya masalah dalam ASI. Seperti hasil kuisioner didapatkan bahwa ibu bekerja yang memiliki bayi usia 0-6 bulan tidak memberikan ASI Eksklusif meskipun tempat kerja memungkinkan untuk memberikan ASI Eksklusif dan diberi waktu istirahat oleh setiap ruangan kerja masing-masing.

Hasil juga didapatkan hasil bahwa dari 21 responden didapatkan 14 responden $(66,7 \%)$ yang memberikan ASI Ekslusif yang mengatakan tersedia fasilitas Pojok ASI 8 orang $(57,14 \%)$ dan mengatakan ada penambahan waktu istirahat sebanyak 4 orang (19\%). Untuk ibu bekerja yang memiliki bayi usia 0-6 bulan direkomendasikan untuk tetap memberikan ASI secara Ekslusif. Jika suami dan istri sama-sama sedang bekerja, akan lebih baik juga ada kerja sama antara suami dan istri mengenai pengasuhan anak dan mengawasi anak. Jika sudah ada kerja sama antar suami dan istri, responden sebaiknya 
Received: 05 OKtober 2020 :: Accepted: 09 Oktober 2020 :: Published: 31 Oktober 2020

memanfaatkan fasilitas Pojok ASI yang ada ditempat kerja dan waktu istirahat yang diberikan untuk memerah ASI.

\section{KESIMPULAN}

Kesimpulan pada penelitian ini adalah :

1. Mayoritas Responden berusia 26-30 tahun, berpendidikan terakhir D3, dan memiliki bayi usia 0-2 bulan.

2. Terdapat hubungan dukungan suami dengan pemberian ASI Eksklusif dengan nilai $p$-value $(0,024<0,05)$.

3. Tidak terapat hubungan tersedianya fasilitas pojok ASI dan penambahan waktu istirahat dengan pemberian ASI Ekslusif karena nilai $p$-value > 0,05 .

4. Terdapat pengaruh dukungan suami terhadap pemberian ASI Ekslusif dengan nilai $\mathrm{p}<0,05$, yaitu nilai $\mathrm{p}=0,012$ dan $\mathrm{t}$ hitung $>\mathrm{t}$ tabel $(2,792>0,814)$.

5. Terdapat faktor yang paling dominan berpengaruh terhadap pemberian ASI Eksklusif dengan menggunakan uji regresi liniar sederhana (simple linear regreassion) dengan melewati tahap seleksi dengan syarat nilai $p$ value $<0,025$ pada uji bivariate.

\section{DAFTAR PUSTAKA}

Habiba, S. (2016). Faktor-Faktor yang Mempengaruhi Pemberian ASI Eksklusif di Wilayah Kerja Puskesmas Kebakkramat II Kabupaten Karanganyer Tahun 2016. Semarang: Universitas Negeri Semarang.

Infodatin. (2018). Menyusui Sebagai Dasar Kehidupan. Jakarta: Pusat
Data dan Informasi Kementrian Kesehatan RI.

Kemenkes RI. (2018). Metodologi Kesehatan. Pusat Pendidikan Sumber Daya Manusia Kesehatan Badan Pengembangan dan Pemberdayaan Sumber Daya Manusia Kesehatan.

Kusumaningram, T. (2016). Gambaran Faktor-Faktor Ibu yang Tidak Memberikan ASI Eksklusif di Desa Cempokosawit Kabupaten Boyolali. Surakarta: Universitas Muhammadiyah Surakarta.

Notoatmodjo, S. (2014). Promosi Kesehatan dan Ilmu Perilaku. Jakarta: Rineka Cipta.

Riskesdas. (2018). Hasil Utama Riskesdas 2018. Jakarta: Kementrian Kesehatan RI.

Septiasari, Y. (2017). Pengaruh Pekerjaan Ibu Terhadap Ststus Pemberian ASI Ekslusif. Jurnal Ilmu Kesehatan.

Sutrisno. (2015). Ketersediaan Ruang Menyusui Terhadap ASI Eksklusif pada Ibu Bekerja di Sleman Yogyakarta. Yogyakarta: STIKes Aisyiyah Yogyakarta.

WHO. (2016b). Infant and Young Child Feeding. World Health Organization.

WHO. (2018). Infant Nutrition. Geneva, Swiss: World Health Organization. 